\title{
Culture, Race, and Hierarchy
}

\author{
Mary-Jo DelVecchio Good
}

Published online: 6 April 2013

(C) Springer Science+Business Media New York 2013

I read these essays with immense appreciation for the creative construction of reflective analyses, elaborated through conversation between ethnographers and academic physicians, as designed and realized by the special issue's editors, Elizabeth Carpenter-Song and Sarah Willen, and their collaborating authors. I also appreciate the authors' frankness in critical reflection, exposing, and puzzling over the conflicts and "pitfalls" in the pedagogical interventions discussed and their rise to the challenge set by Willen, drawing on George Devereux, to "lift the hood." I approach my commentary having spent decades studying the culture of medicine in its many guises, at times through observations and surveys but mostly through conversations with physicians across the globe from highly diverse institutional and societal settings. I have published with some of these physicians representing a conversation internal to our projects, most recently in Shattering Culture, American Medicine Responds to Cultural Diversity (Good et al. 2011b), for which Willen and Hannah are contributors and co-editors and Bullon and Carpenter-Song contributors.

I have often engaged collaborating physicians who were also subjects of my research in jointly authored essays, for instance on psychiatry, oncology, end-of-life research primary care, HIV in Africa, maternal and child health, global health, and medical education. A few examples of essays in which I drew in my clinician collaborator-subjects as co-authors include "American Oncology and the Discourse on Hope" (1990); "Oncology and Narrative Time" (1994); "Conversations with Oncologists" (1995); "Clinical Realities and Moral Dilemmas" (1999); "Physicians Narratives at the End of Life" (2004); "The Culture of Medicine and Disparities in Healthcare by Race, Ethnicity and Social Class" (2003, 2004); and "Communication Barriers among Physicians in Care at the End of Life" (2012). As primary author, my voice most often dominated as I wove the clinicians' voices into the text. What is refreshing and unique in this issue of Culture, Medicine, and Psychiatry are

M.-J. D. Good ( $\bowtie)$

Department of Global Health and Social Medicine, Harvard Medical School, Boston, MA, USA

e-mail: maryjo_good@hms.harvard.edu 
the critical conversations, as well as reflective analyses on pedagogical projects, that are carried on not through jointly authored essays, but rather via independent contributions in which disciplinary voices speak to each other through the volume's structure of paired essays. As readers, we too can engage in an expansive discourse across the disciplinary and positional divide as we interpret the emergent links within each pair of positional essays. Thus, we come to a dominant theme throughout: the often unexplicated "under the hood" or silent discourse on race, hierarchy, and privilege, and the pedagogical difficulties in addressing these issues directly in medical educational settings.

\section{Pair One: Teaching Cultural Sensitivity or Cultural Competence}

Sarah Willen and Antonio Bullon set the pace with their paired essays on an ethnographic study that began with Willen's observations of a required cultural sensitivity course for a (highly multicultural) group of psychiatry residents in which she not only attended the course sessions, but also interviewed at length the residents and the two faculty psychiatrists who were its committed teachers. In puzzling over the course's limitations with residents and faculty (Willen et al. 2010), she was drawn to George Devereux's warning that, as she puts it, "if unacknowledged, unspoken and unconscious influences have the capacity to torpedo interaction." This warning helps her make sense of the strong emotional reactions of residents, including one who claimed the course each week would open "a big huge gaping wound." In framing the residents' reactions through a lens of transference and counter-transference, Willen links the "gaping wound" imagery to the awkwardness of race talk that invades social spaces in American society. Is the awkwardness perhaps related to the exceptional diversity among participants? Emotions exploded in particular in a session led by an African-American psychiatrist, who presented four cases that illustrated the depth of American racism and "horrendous health disparities" of those not "relatively privileged." Willen ends with reflections on key recommendations drawn from residents: "safe spaces," collegial experiential learning, robust and nuanced concepts of culture, and avoidance by faculty of assumptions about residents and their cultural interest and knowledge. I ask: what is a safe space in today's American health care institutions?

Personally, the residents' comments amuse me since they echo those of psychiatry residents and medical students from a much earlier era at the University of California, Davis in the late 1970s and early 1980s, where I was at times forced to teach dreaded courses on race and ethnicity along with an anthropologist (my Midwestern Mennonite husband) and a male psychiatrist (who was Mexican-ItalianAmerican but could barely speak a word of Spanish). Only when we devised courses in collaboration with medical students, psychology graduate students, and psychiatry and family medicine residents did I feel some satisfaction with the pedagogical experience and "safe" from derision. My recommendation for all medical education on culture is make it collaborative and seductively elective!

Antonio Bullon's response to Sarah Willen's paper is remarkable for its frank honesty and personal insight. Upon moving from Peru to the U.S. for residency 
training, Bullon became a "designated minority" and "the other" which intrigued him, and as a social justice activist and new graduate from psychiatry residency, he was asked to teach a "culture course" in partnership with two colleagues who were also recent residency graduates and social activists with college educations in the humanities. Bullon describes how after putting together "the course of their dreams" they would have liked to have had as residents, they were dismayed by "the lukewarm responses of many residents year after year." Although Bullon looks for sources of difficulty and suggests ways such a course might be improved to make it more relevant to residents' immediate concerns, the three faculty members were influenced by the civil rights era and perspectives on social justice and were "very different from the generation of young physicians we were training." Although trained to de-escalate angry patients, he writes, "we had no models in how to defuse tension between doctors after a heated discussion about race and privilege." I empathize with his argument for training in conflict resolution and negotiation skills as I reflect on my own past experiences. However, I disagree with his recommendations that older clinicians should teach such a course and that experience is the solution, as I recall 36 years of observing and being engaged in the missteps of clinical and social science faculty, young and old, who end up having to teach cultural competence courses. The authors of these paired essays lead us to ask if it is not precisely the heated debates, transferences, and counter transferences generating emotional distress and anxiety that should be the essence of such courses, in which part of learning about "culture and race and privilege" involves speaking about that which is normally unvoiced and sometimes arguing very loudly about it. Is learning space not safe space but rather anxious space and at times hot space? Can one tolerate this heat while erasing negative consequences of the hierarchy of power? Might not managing relationships with fellow residents who intensely and emotionally disagree and experience "cultural sensitivity cases" differently simply be part of learning to be a culturally competent psychiatrist in American society?

\section{Pair Two: Residency Research Training Collaboration}

The next pair of essays, Carpenter-Song and Whitley's "Behind the Scenes of a Research and Training Collaboration: Power, Privilege, and the Hidden Transcript of Race" and Malik's “A Collaboration Between a Historically Black University (HBU) and an Ivy League Psychiatric Research Center: A Psychiatrist's Reflections of the Impact on Residency Training," delve deeply into the issues of "assumptions and perspectives on race and identity" as well as organizational culture, disciplinary divides, and deeply felt and difficult to discuss inequalities of privilege.

I was struck again by the authors' reflective openness in talking about the "under the hood" or "behind the scenes" difficulties of collaboration between a rich Ivy League University (ILU) and rural bastion of white privilege, and an urban, HBU. When the authors write about the hostility of senior psychiatry faculty who dismissed the Ivy League anthropologist-researchers "with contempt" - asking, "how could we as non-clinicians understand anything about mental illness? What 
was the point of such "soft research"? "How could we dare to critique psychiatry?" (ms p 12) - I too felt discomfort, empathizing to my core as the authors described their own discomfort. The essay builds, illustrating the difficulties of getting residents at the $\mathrm{HBU}$ to buy into the research training experiences offered by this collaboration. What emerges is not only a clash of institutional cultures, but the American "gaping wound" of differences of race, and disparities of privilege. Were the senior HBU psychiatrists perhaps voicing something else when they questioned the "right" of the white Ivy League anthropologists to enter their psychiatric turf? This difficult and uncomfortable story unfolds as the authors explore issues of privilege and race, hierarchy and authority, and the cultural differences between these two educational institutions - "all this to say that things that are easy at [the ILU] and ... taken for granted-are often problematic at [the HBU]." Furthermore,

issues of race, as they are experienced in the context of our interactions with one another, are not made explicit. We have never, as a team, come together to discuss our perspectives on race and our lived experiences of coming from diverse backgrounds. Instead race only explicitly enters into the collaboration as part of the official transcript of our research and training efforts. Yet hidden dynamics of power and privilege shape day to day interactions among members of the Collaboration. (p. $21 \mathrm{~ms}$ )

Mansoor Malik, the training director of the psychiatry residency program at the HBU, was a psychiatry fellow at the ILU following his residency training first in the United Kingdom and then at a Philadelphia hospital in the U.S. He writes directly about his own ethnicity and minority status, noting that he is an immigrant physician from Pakistan and a member of the Ahmadiyya, a minority Muslim sect persecuted in Pakistan (and elsewhere in the Muslim world). He notes that "cultural competency has assumed an ever increasing role in our curriculum" and that "we take care to select residents that are sympathetic and possibly committed to reducing racial disparities in mental health." His goal is the collaborative program goal-to build research capacity in minority and in particular African-American mental health. His view of the influence of the summer training program on residents is somewhat startling. He notes,

perceiving that the introduction of anthropological methods of inquiry was uncovering the latent anxieties about power sharing and hierarchy within the residency program, we initiated a regular confidential process group. ... the residents have come to appreciate anthropological methods and theory that place disparities research in the context of social justice and promote a sophisticated understanding of 'culture' and its role in disparities. (p. $8 \mathrm{~ms}$ )

As a bridging figure between the two institutions, and perhaps between black and white America as immigrants are at times able to do, Malik identifies negative aspects of the culture of hierarchy between senior faculty and residents at the HBU and introduces the uncomfortable challenges it poses for the research training collaboration. While not going as far "under the hood" as the Ivy League anthropologists, his essay sets forth warnings to entrenched hierarchies to step aside and let new researchers grow. 


\section{Pair Three: Patrolling Your Blind Spots and A Safe Place to Speak}

Seth Hannah, Elizabeth Carpenter-Song, and Roxana Llerena-Quinn offer commentary on a faculty development course to reduce bias. As Roxana notes in her essay, the course in its third iteration replaced one that, in my experience, was driven by the 1960s generation grounded in social justice and civil rights. The pedagogical strategy of this course, Hannah and Carpenter-Song tell us, is promoting self-awareness and introspection and creating safe spaces in which to speak without blame or criticism to reduce bias. Llerena-Quinn highlights the importance of reducing bias and disparities in treatment in line with the agenda set forth in the Institute of Medicine's "Unequal Treatment" (2003) and national policies at the National Institutes of Health, as well as local policies to reduce health disparities by reducing disparities in medical care and treatment that may be caused by bias and prejudice. Hannah and Carpenter-Song attended the twelve meetings of the course and had informal conversations with participants and instructors as well as formal interviews with three instructors and five participants. Through interviews and their own observations, the ethnographers "lift the hood," exploring the motivation and responses of participants and the philosophy of the course founders. Llerena-Quinn, one of the course instructors and developers, welcomes the feedback and again sends out a clarion call for a commitment to social justice and reduction in disparities. She argues for cultural sensitivity and knowledge as well and for cultural competence in the widest sense, despairing at supervisors who dismiss those who are too poor to be well served. Llerena-Quinn draws on the movements against disparities and inequalities in mental health care-calling attention to "Culture Matters" in reducing disparities and "Unequal Treatment."

This pair of essays presents a positive and contemporary intervention, one that can perhaps be improved given the newness of the course format. Yet the course was a success. Why? The course is voluntary! Faculty who join for the twelve sessions are committed to introspection in a safe space and are interested in culture and reducing blind-spot bias, or what the authors note is now referred to as "ethical self fashioning." The detailed ethnographic description of the course, its highly successful small group discussions, its over-all agenda, and the participants' positive responses show that the small group method achieved the instructors' pedagogical goals. The authors note a steadfast commitment to social justice and reducing health disparities by minimizing bias and exploring one's own negative bias and cultural identities. All three authors argue for a more robust link between a focus on the micro-aspects of the self and macro structural concerns.

What a marked contrast this pair of essays is to the discomfort generated in the Willen and Bullon essays on the residency training course. What are the essential differences between this faculty seminar and the residency seminar? My own reflections are shaped in part by a short stint in an earlier version of the course, which was established many years ago by one of the faculty leaders of the New Pathway revolution in medical education at Harvard Medical School. Dan Goodenough, a highly esteemed and popular professor with students and faculty, offered a course on racism and self-awareness designed to reduce racism and bias. The ideological core of the course was a commitment to social justice, civil rights, 
redressing prejudice and inequalities for minorities, and affirmative action. At the time we spoke about the poor, minorities, and inequalities rather than disparities. We were a multicultural group of faculty members, but only one of us was African American, a highly esteemed surgeon. We anthropologists soon excused ourselves from yet one more evening we could not spare given an overload of nighttime seminar obligations, but the respect Dan held for others, and faculty for him, was extraordinary. This was a 60s generation course in its ideology and leadership. The participants and those who returned and collaborated in various versions of the course were enchanted with the safe space for hard talk that Dan and his colleagues created.

The contrasts with the residency course are curious. Dan's course, much like the one Hannah, Carpenter-Song, and Llerena-Quinn describe, was elective; the psychiatry residency course was not. The faculty courses were collaborative and small group based and focused on the self in a 60s sort of way, and the residency course was not. The faculty course was a place where young and old and junior and senior faculty met to speak about themselves, and the residency course was not. Dan's course, and perhaps this course too, was playful; it was time for faculty imagination to play out. The residency course was also initially for the faculty a time for imagination to play out, but the residents were not in a space to relish the intellectual play. One wonders what vulnerabilities made it so hard for them to enjoy and engage what their young faculty found so interesting? Perhaps third year residents are not worthy of such a course? Perhaps the rule of law rather than education is what matters?

\section{Pair Four: The Canadians and Working with Culture Seminar}

The Canadians in Montreal have their own fascinating cultural modalities for teaching clinical cultural psychiatry, where diversity is the message. Authors Jaswant Guzder and Cécile Rousseau, cultural psychiatrists, offer a fine essay on the "Diversity of Voices" in their summer seminars on Working with Culture. Psychiatrist Laurence Kirmayer comments on their "distinctive pedagogical values and orientations." The Working with Culture Seminar, which takes place as part of a month long program in Social and Transcultural Psychiatry, is case based and uses an all-encompassing biopsychosocial model. The case however holds the center, and the conversation Rousseau and Guzder seek to create interweaves the voices of seminar teachers and participants who engage each other in a zone of "cultural safety." Discussing therapist-client relationships and therapeutic process is at the core of their agenda, and cultural competency training is incorporated into the whole model. The course sounds like summer intellectual fun, engaging, bonding, and conversing about "uncertainty and non-closure" in therapeutic work. The "universal and culturally specific are woven through the seminars" (p. $11 \mathrm{~ms}$ ) even as specific modes of therapeutic engagement are taught by visiting faculty. Guzder and Rousseau hope the seminars will provide a place for critical thinking and the emergence of new ideas useful in structuring clinical training experiences and managing local cultural challenges. 
Kirmayer, highlighting Hannah's concept of hyperdiversity (Hannah 2011; Good et al. 2011b) to reflect on Canada's multicultural state, notes that "for the last 100 years, 15-20\% of Canadians were born outside Canada and that in a sense everyone is a hyphenated Canadian." He notes how Guzder and Rousseau focus on collective identities and the larger political dynamics of drawing diverse perspectives from seminar participants (see Bibeau (1997) on multicultural Quebec and the First Nation of Wasena-Waseya (2008)). He also sees Rousseau and Guzder as successful, confirming the seminar has created a community of practice that supports culturally informed and politically aware clinicians, offering a broader role for clinicians as advocates and partners with patients and community systems. Perhaps the seminar, which sounds intellectually fun and invigorating, might enhance the role of traditional therapists, whose cultural and professional authority may well be eroding in Canada as it is in the United States, where institutional pressures are leading to compromises in terms of check box psychiatry (Bullon et al. 2011) and financial pressures (Good et al. 2011a, b, p. 22; Hannah et al. 2011).

\section{References}

Bibeau, Gilles

1997 Cultural Psychiatry in a Creolizing World: Questions for a New Research Agenda. Transcultural Psychiatry 34(1): 9-41.

Bullon, Antonio, Mary-Jo DelVecchio Good, and Elizabeth Carpenter-Song

2011 Paper Life: Documentation Practices in the Care of Minority and Low-Income Patients. In Shattering Culture: American Medicine Responds to Cultural Diversity. Mary-Jo DelVecchio Good, Sarah S. Willen, Seth Donal Hannah, Ken Vickery, and Lawrence T. Park, eds. New York: Russell Sage Foundation.

Good, Mary-Jo DelVecchio, Nina M. Gadmer, Patricia Ruopp, Matthew Lakoma, Amy M. Sullivan, Ellen Redinbaugh, Robert M. Arnold, and Susan D. Block

2004 Narrative Nuances on Good and Bad Deaths: Internists' Tales from High-Technology Work Places. Social Science \& Medicine 58(5): 939-953.

Good, Mary-Jo DelVecchio, Byron J. Good, Cynthia Schaffer, and Stuart E. Lind

1990 American Oncology and the Discourse on Hope. Culture, Medicine and Psychiatry 14(1): 59-79.

Good, Mary-Jo DelVecchio, Cara James, Byron J. Good, and Anne E. Becker

2003 The Culture of Medicine and Racial, Ethnic, and Class Disparities in Healthcare. In Unequal Treatment: Confronting Racial and Ethnic Disparities in Healthcare. Brian D. Smedley, Adrienne Y. Stith, Alan R. Nelson, eds., pp. 594-625. Washington, DC: National Academies Press.

Good, Mary-Jo DelVecchio, Tseunetsugu Munakata, Yasuki Kobayashi, Cheryl Mattingly, and Byron J. Good

1994 Oncology and Narrative Time. Social Science \& Medicine 38(6): 855-862.

Good, Mary-Jo DelVecchio, Esther Mwaikambo, Erastus Amayo, and James M'Imunya Machoki

1999 Clinical Realities and Moral Dilemmas: Contrasting Perspectives from Academic Medicine in Kenya, Tanzania, and America. Daedalus 128(4): 167-196.

Good, Mary-Jo DelVecchio, Sarah S. Willen, and Seth Donal Hannah

2011a Shattering Culture, An Introduction. In Shattering Culture: American Medicine Responds to Cultural Diversity. Mary-Jo DelVecchio Good, Sarah S. Willen, Seth Donal Hannah, Ken Vickery, and Lawrence Taeseng Park, eds., pp. 1-30. New York: Russell Sage Foundation.

Good, Mary-Jo DelVecchio, Sarah S. Willen, Seth Donal Hannah, Ken Vickery, and Lawrence T. Park, eds.

2011b Shattering Culture: American Medicine Responds to Cultural Diversity. New York: Russell Sage Foundation. 
Good, Mary Jo DelVecchio, Irene Kuter, Simon Powell, Herbert C. Jr. Hoover, Maria E. Carson, and Rita Linggood

1995 Medicine on the Edge: Conversations with Oncologists. In Technoscientific Imaginaries: Conversations, Profiles, and Memoirs. George E. Marcus, ed., pp. 129-152. Chicago: University of Chicago Press.

Hannah, Seth

2011 Clinical Care in Environments of Hyperdiversity In Shattering Culture: American Medicine Responds to Cultural Diversity. Mary-Jo DelVecchio Good, Sarah S. Willen, Seth Donal Hannah, Ken Vickery, and Lawrence T. Park, eds., pp. 35-69. New York: Russell Sage Foundation.

Hannah, Seth Donal, Lawrence Taeseng Park, and Mary-Jo DelVecchio Good

2011 Physicians' Perspectives on Financial Barriers to Equitable Care. In Shattering Culture: American Medicine Responds to Cultural Diversity. Mary-Jo DelVecchio Good, Sarah S. Willen, Seth Donal Hannah, Ken Vickery, and Lawrence Taeseng Park, eds., pp. 217-234. New York: Russell Sage.

Muhaimin, Amalia, Mary-Jo Delvecchio Good, Yati Soenarto, and Retna Siwi Padmawati

2012 Communication Barriers among Physicians in Care at the End of Life: Experience from a Postgraduate Residency Training in Java, Indonesia. Asian Bioethics Review 4(2): 102-114.

Tousignant, M., A. Laliberté, G. Bibeau, and D. Noël

2008 Comprendre et agir sur le suicide chez les Premières Nations: Quelques lunes après l'initiation. Frontières 21(1): 113-119.

Willen, Sarah S., Antonio Bullon, and Mary-Jo DelVecchio Good

2010 Opening Up a Huge Can of Worms: Reflections on a "Cultural Sensitivity" Course for Psychiatry Residents. Harvard Review of Psychiatry 18(4): 247-253. 